ARTIGO

Recebido em: 10/03/2017

Aceito em: 08/11/2017

\title{
Jesse Shera e sua contribuição para o campo da Biblioteconomia e Ciência da Informação
} Jesse Shera and his contribution to the field of Library and Information Science

\author{
Keitty Rodrigues VIEIRA (keitty_rodriguesvieira@hotmail.com)* \\ Elaine Rosangela de Oliveira LUCAS (lanilucas@gmail.com)** \\ * Graduada em Biblioteconomia - UDESC. \\ ** Professora do Departamento de Biblioteconomia e Programa de Pós-Graduação em Gestão da \\ Informação- UDESC.
}

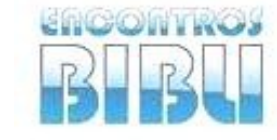

v. 23, n. $51,2018$. p. $17-30$

ISSN 1518-2924

Resumo: Este trabalho tem por objetivo apresentar a contribuição de Jesse Shera para o campo da Biblioteconomia e Ciência da Informação. Pretende, por meio de revisão teórica, abordar aspectos relacionados com os movimentos influentes na corrente humanística da Ciência da Informação, permeando suas vertentes históricas, incluindo sua consolidação e dando destaque para o movimento conhecido como Escola de Chicago, que exerceu grande influência na repercussão da corrente humanística do campo em estudo. Aborda curiosidades de Shera, sua vida e suas obras. Por fim, são expostas as influências do autor para o campo da Biblioteconomia e CI atual, bem como são oferecidos caminhos para que novas pesquisas possam ser desenvolvidas com base na revisão teórica realizada, de modo a instigar que outros pesquisadores tenham um olhar mais apurado sobre a relevância de Shera.

Palavras-chave: Jesse Shera. Ciência da Informação - Vertente humanística. Escola de Chicago. Biblioteconomia e Ciencia da Informação.

\begin{abstract}
This paper aims to present the contribution of Jesse Shera to the field of Library and Information Science (LIS). Through a theoretical revision it intends to address aspects related to the movements which are influential in the humanistic part of Information Science, permeating its historical aspects, including its consolidation and highlighting the movement known as the Chicago School, which exerted a great influence on the humanistic repercussion of the discussed field of study. We discuss curiosities about Jesse Hauk Shera, his life and his works. Finally, we show the influences of Jesse Shera on the fields of the current LIS and offer ways in which new research may be developed based on the theoretical revision carried out, in order to encourage other researchers to have a closer look at the relevance Shera in this field.
\end{abstract}

Keywords: Jesse Shera. Information science - humanistic aspect. Chicago School. Library and Information science. 


\section{INTRODUÇÃO}

A Ciência da Informação (CI) e a Biblioteconomia possuem uma relação explicada apenas por meio do resgate ${ }^{1}$ histórico de ambas. Pensar na história é algo importante que nos ajuda a conhecer o novo e a compreender algumas ações, além de nos instigar, cada vez mais, nas pesquisas sobre um tema, pois a compreensão de nossos atos como profissional e ser humano são influenciados pela história envolta ao nosso fazer.

A chegada de novas ferramentas e, principalmente, uma nova visão acerca da organização, recuperação e disseminação da informação são recebidas pelos bibliotecários com alguma resistência, na opinião de Silva e Freire (2012). Para os autores, a quebra de paradigma que a CI apresentou com o conceito de gerenciamento da informação independente de seu formato, resultou em fortes implicações para os profissionais da área, gerando resistência que ainda hoje persiste em alguns bibliotecários.

A origem da área da CI ainda é muito debatida, bem como sua relação com a Biblioteconomia. Em ambas, alguns conceitos abordados nos fazem refletir sobre suas respectivas origens e os aspectos semelhantes entre elas, a ponto de alguns autores, como Le Codiac (2004), Macedo (2013) e Silva (2012), entre outros, sugerirem que a Ciência da Informação é uma 'evolução da Biblioteconomia'. Na maioria das vezes, a CI é atrelada às novas tecnologias de informação e comunicação que se utilizam do meio digital para gerar, organizar e disseminar a informação, porém, esquece-se de que toda informação tratada, organizada e disseminada possui um único alvo: o usuário.

Para este artigo, acredita-se que a discussão conceitual e epistemológica que envolve a origem das áreas da Ciência da Informação e da Biblioteconomia, assim como seu entrelaçamento, desviaria do propósito e da motivação da pesquisa. Adotou-se, portanto, o termo 'campo da Biblioteconomia e Ciência da Informação' no sentido da teoria de Pierre Bourdieu ${ }^{2}$, abarcando, assim, as áreas independentemente de suas concepções histórico-epistemológicas e possibilitando o olhar a esse campo como lugar de reunião de agentes que tratam, organizam e disseminam a informação com foco no usuário, e é justamente esse lado humanístico ${ }^{3}$ que será abordado com ênfase aqui.

Para que seja possível a compreensão do surgimento da Biblioteconomia humanística e para os aspectos humanísticos presentes na Ciência da Informação, faz-se necessário o conhecimento acerca da Escola de Chicago, movimento fundamental para a ascensão de diversos pesquisadores da área de CI e para a sua consolidação. É desse movimento que surge a mais atual vertente humanística ${ }^{4}$ do

\footnotetext{
${ }^{1} \mathrm{O}$ termo resgate, nesta pesquisa, refere-se à visão histórica no sentido de retomar algo ou alguém do passado, ou seja, dar luz à sua obra.

2 Para Bourdieu (2004, p. 22-23), "todo campo é um campo de forças e um campo de lutas para conservar ou transformar esse campo de forças".

${ }^{3}$ Há diferença entre as palavras 'humanística' e 'humanista'. Humanística está relacionada à propriedade ou característica das ações ou, também, a efeitos das ações dos humanistas. Humanista é utilizada para se referir a um simpatizante ou adepto do humanismo. Como neste trabalho o foco será para as ações e ideologias de Jesse Shera que influenciaram no campo da Biblioteconomia e na CI, adotaremos a palavra "humanística" por melhor corresponder à proposta desta pesquisa. (Fonte: Dicionário informal, 2016)

${ }^{4}$ Nesta investigação, trabalhou-se com a visão da existência de duas correntes no campo da Biblioteconomia e CI: a corrente humanística e a corrente tecnicista. Quando se fala em 'corrente humanística', para esta pesquisa, tem-se como foco as atividades que possuem o usuário como ponto principal (como o serviço de referência e a própria recuperação da informação priorizando a autonomia desse usuário). Quando se fala da corrente tecnicista, abordam-se atividades relacionadas ao núcleo duro da profissão, em que o foco é o tratamento da informação, e não a relação dessa informação com o usuário.
} 
campo da Biblioteconomia e $\mathrm{CI}$, por isso torna-se importante conhecê-lo para melhor compreender as influências humanísticas que possuímos atualmente.

Dentre vários estudiosos influentes na evolução do campo, observa-se a existência de um, em especial, que contribuiu sobretudo no fortalecimento da vertente humanística: Jesse Shera. Embora não seja muito abordado na literatura brasileira, o teórico tem uma importante influência quando se pensa nas questões sociais das práticas biblioteconômicas, pois propôs algumas teorias relacionadas ao lado humanístico da profissão, que serão abordadas adiante.

Essas teorias sugeridas por Shera ao longo de sua trajetória como bibliotecário e pesquisador do campo da Biblioteconomia e Ciência da Informação irão esclarecer aspectos históricos que perpassam por esse campo. A partir disso, pretende-se que possa ser feita uma ligação teórica acerca do cunho humanístico presente no campo atualmente.

Serão abordados a história do movimento da Escola de Chicago bem como seu modelo de pesquisa e seus principais pesquisadores, a visão humanística da Biblioteconomia proveniente da Escola de Chicago, a vida e a obra de Jesse Shera e suas contribuições no campo da Biblioteconomia e Ciência da Informação.

É oportuno conhecer a influência de Jesse Shera, tendo em vista a necessidade de pensar este Campo em seu fazer social. A missão do bibliotecário, abordada por autores como Ortega y Gasset (1967), Saracevic (1996) e Lankes (2013) na literatura, baseia-se no aspecto humanístico da profissão, apresentar um pensador influente nessa visão é relevante, já que conhecendo a vertente humanística e o pensamento de seus apoiadores é possível entender melhor o tempo presente e aprimorar o fazer biblioteconômico atual.

\section{VISÃO HUMANÍSTICA DA BIBLIOTECONOMIA E A ESCOLA DE CHICAGO}

Araújo (2011) menciona que a Biblioteconomia, a Documentação e a Arquivologia são áreas preocupadas com as técnicas que cuidam do acervo e que, a partir delas, torna-se possível proporcionar uma reflexão científica externa a essas áreas. 0 autor separa, ainda, a criação de tais áreas em basicamente três momentos: o primeiro, com foco no conteúdo; o segundo, com foco na necessidade de profissionalização; e o terceiro, com foco nas técnicas advindas dos manuais e guias criados na época.

Os manuais e tratados, em especial os bibliográficos criados entre os séculos XV e XVII,, como, por exemplo, o Liber de scriptoribus ecclesiasticis (1494), de autoria de Johannes Trithemius (ARAUJO, 2015), voltavam-se para o conteúdo dos acervos. Nessa primeira fase, constroem-se conhecimentos voltados para a literatura, a filosofia, a história e a arte sobre os conteúdos guardados nas instituições. As regras eram focadas na preservação e conservação física do material e envolviam estratégias de descrição formal desses documentos.

No segundo momento, verifica-se a necessidade de existir um pessoal qualificado para trabalhar em tais áreas. Essa 'exigência' de qualificação profissional é advinda da Revolução Francesa e demais revoluções burguesas que marcam a chegada da Modernidade. É nesse contexto, então, que surgem os primeiros cursos profissionalizantes.

A terceira e última fase mencionada por Araújo (2011) diz respeito à criação de manuais e guias voltados para a prática profissional. Esses manuais criados ao longo de todo o século XIX estabelecem o projeto de constituição científica da Biblioteconomia, pois privilegiam os procedimentos técnicos de intervenção, isto é, a parte da catalogação e ordenação dos acervos, por exemplo. Portanto, entre o final do século XIX e o início do século XX, a Biblioteconomia é vista como sendo principalmente uma área tecnicista. 
Fonseca (2007) afirma que o excesso de tecnicismo presente na Biblioteconomia durante o período citado ocasionou o afastamento dos bibliotecários em sua relação com seu usuário. A vertente tecnicista aflorada entre os séculos XIX e XX influenciou na visão dos cursos de Biblioteconomia surgidos nessa época bem como no modelo adotado, que poderiam seguir os traços humanísticos franceses ou norte-americanos. Esses modelos são capazes de distinguir a visão da Biblioteconomia - até mesmo dentro de um mesmo país quando seus cursos de graduação optam por abordar aspectos específicos de alguma vertente teórico-epistemológica na hora da criação da grade curricular, assim como ocorreu no Brasil.

Segundo Almeida e Baptista (2013), o primeiro curso de Biblioteconomia brasileiro, criado na Biblioteca Nacional em 1915, foi baseado no modelo francês, que possuía traços humanísticos. Em contrapartida, o curso criado em 1929, na cidade de São Paulo, voltava-se para o tecnicismo com base no modelo norteamericano.

Aos poucos, a vertente humanística vai se fazendo cada vez mais presente no contexto biblioteconômico a partir do momento que a importância da biblioteca passa a ser com a disseminação da informação, e não apenas com a guarda documental.

Os movimentos relacionados com a criação das bibliotecas públicas que permitissem o acesso a todos, e não somente a um público elitizado, foi fundamental para a concepção da visão humanística, tanto para as bibliotecas quanto para seus profissionais. A influência francesa na visão humanística da área, de acordo com Guimarães (1997), é proveniente da ligação da École Nationale des Chartes, em Paris, com a origem do curso.

Vê-se, portanto, que a Biblioteconomia transita entre as vertentes tecnicistas e humanísticas durante toda a história de consolidação da área. Bufrem (1985, p. 113) afirma que "as transformações sociais que culminaram com as bibliotecas públicas e gratuitas e com as redes de bibliotecas são frutos, por sua vez, das preocupações democráticas e das próprias reivindicações populares". Enfim, a Biblioteconomia atual, que se preocupa com o bem-estar do usuário e seu acesso à informação e que avalia seus serviços por meio de estudos de usuários, por exemplo, ressalta a importância da visão humanística, inclusive entre as atividades técnicas, tendo como pressuposto que a própria classificação adotada em cada unidade de informação deve ser escolhida com base no tipo de usuário que atenderá (GIGANTE, 1995).

Entre os movimentos conhecidos que influenciaram o campo da Biblioteconomia e CI está o movimento da Escola de Chicago, que nasce na Universidade de mesmo nome e que reverberou na voz de Jesse Shera.

Fundada em 1895, nos Estados Unidos da América (EUA), a University of Chicago foi estabelecida a partir da doação de John D. Rockefeller.

Com um número reduzido de professores, segundo Becker (1996), um dos integrantes do corpo docente era Albion Small, que havia sido diretor de uma pequena faculdade do estado de Maine (EUA). Em meio ao problema vivido pelos EUA devido à recessão, Small, interessado na reforma social, teria criado um Departamento de Sociologia com base no modelo alemão ${ }^{5}$ e esse pensamento o seguiu, junto com seus alunos, para a University of Chicago.

Small, assim como outros pesquisadores que desenvolviam seus estudos nas redondezas de Chicago, acabou influenciando outros docentes da própria

\footnotetext{
${ }^{5} \mathrm{O}$ modelo alemão era proveniente da Escola de Frankfurt, a qual consistia, segundo Ribeiro (2016), em um grupo de intelectuais que produziam um pensamento chamado de Teoria Crítica que buscava a união entre o trabalho empírico e teórico de modo a tratar o marxismo a partir de uma visão autorreflexiva.
} 
universidade e adeptos do modelo proposto pelo grupo. Diversos departamentos de Sociologia foram criados em outras universidades, tendo o Departamento de Sociologia da University of Chicago influenciado a visão sociológica adotada pelos demais departamentos da instituição.

A partir dessa influência sociológica, por volta dos anos 20, surge a famosa Escola de Chicago, basicamente um movimento que nasceu nas dependências da University of Chicago, mas que não se restringiu aos limites da instituição em razão da grande influência de pesquisadores de fora dela. Cabe ressaltar que, no Brasil, o termo 'Escola de Chicago' representa o que internacionalmente é também conhecido por 'Escola de Sociologia de Chicago' ou 'Escola Sociológica de Chicago'6.

Segundo Ortega (2004, p.12), "a Biblioteconomia nos Estados Unidos, no final do século XIX, foi marcada por sua sedimentação e por inovações técnicas e tecnológicas". A partir dessa sedimentação, começa-se a pensar a Biblioteconomia por duas visões: a primeira, visando à representação da informação (catalogação, indexação e demais áreas diretamente ligadas ao processamento técnico) e a outra, enfatizando o desenvolvimento da Escola de Biblioteconomia de Chicago, que até então valorizava estudos acerca da recuperação da informação.

Devido aos parâmetros delineados pela Escola de Chicago, que passam a delimitar o modelo de biblioteca nos Estados Unidos da América, a biblioteca começa a ser vista como uma instituição social organizada e definida (SIQUEIRA, 2010)". A biblioteca também incorpora a função de ser facilitadora em relação ao acesso à informação pelo indivíduo usuário.

Na Europa, por volta da década de 30, ocorre um crescimento na publicação de artigos voltados à biblioteca pública em função dos movimentos ligados à expansão dessas bibliotecas e de promoção do acesso à informação por toda a sociedade. No mesmo período, nos EUA, a Biblioteconomia começa a se desenvolver alicerçada em princípios ligados às Ciências Sociais, pois passa a seguir os moldes inspirados pela Escola de Chicago.

É a partir desse momento que a Escola de Chicago ultrapassa as barreiras da University of Chicago e começa a instaurar-se como um movimento de influência humanística que abarca pesquisadores de dentro e de fora da universidade de origem, também influenciando o desenvolvimento da Biblioteconomia para além da instituição.

De qualquer forma, naquela época ainda se via a Biblioteconomia como uma ciência extremamente ligada às técnicas de organização e processamento da informação. Dias (2000) complementa afirmando que essa 'biblioteconomia-ciência' que possui uma preocupação sistemática em chegar a resultados que satisfaçam ou que melhor solucionem os problemas da área também se faz presente na década de 30, com a fundação da Graduate Library School da University of Chicago.

Em 1928, cria-se o primeiro doutorado em Biblioteconomia pela University of Chicago - muito antes do surgimento da Ciência da Informação. É nesse contexto que começam a aparecer as primeiras manifestações dos 'estudos de comunidade' que focavam os grupos sociais.

A University of Chicago, entre as décadas de 30 e 60, foi considerada o centro intelectual da Biblioteconomia nos EUA. Sua abordagem possuía as bases ideológicas da Sociologia e da Educação e, por isso, suas pesquisas evidenciavam a função social da biblioteca e do bibliotecário, reconhecendo a biblioteca como uma "organização social voltada à memória sociocultural”. (SANTOS; RODRIGUES, 2013, p. 126).

\footnotetext{
6 Para esta pesquisa, quando for mencionado o termo 'Escola de Chicago' adota-se a referência do movimento apenas em sua influência para o campo da Biblioteconomia e da CI. Quando for mencionado 'Escola Sociológica de Chicago', refere-se à contribuição do movimento em seu sentido amplo para todos os demais campos do conhecimento.
} 
Porém, com essa perspectiva humanística bastante presente no modelo de pesquisa da universidade e do movimento que ganhava força entre os pesquisadores do campo da Biblioteconomia e CI, muitos criticaram a Escola de Chicago por não sustentar uma abordagem 'científica', pois se afastava das questões relacionadas ao tratamento documentário e às práticas biblioteconômicas ligadas ao caráter tecnicista da profissão.

É importante ressaltar, contudo, que "é com a Escola de Chicago que os problemas relacionados à área da Biblioteconomia começam a ser efetivamente estudados nos Estados Unidos". (SANTOS; RODRIGUES, 2013, p.126).

Alguns pesquisadores defendiam a visão da Escola de Chicago, que apresentava uma Biblioteconomia científica não ligada aos processos técnicos, mas, sim, ao cumprimento das funções sociais da biblioteca e do bibliotecário.

Autores como Butler, Dantons e Williamson acreditavam que o fundamento da biblioteca "se encontra no fato de ela ir ao encontro de certas necessidades sociais" (ARAÚJO, 2011, p.25). Shera, que também partilhava da mesma visão, chega a propor uma disciplina chamada Epistemologia Social.

As menções relacionadas à Escola de Chicago na produção científica brasileira são, de algum modo, resumidas, até por se tratar de um termo informal que não está ligado a uma instituição, embora o contexto de criação do Doutorado em Biblioteconomia na University of Chicago tenha sido um fator influente nos modelos adotados pelos pesquisadores da época. $\mathrm{Na}$ produção científica internacional, se veem grandes dificuldades para encontrar conteúdo sobre o assunto, uma vez que não há uma nomenclatura definida para esse movimento.

Por fim, ressalta-se que a Escola de Chicago influenciou a vertente humanística no campo da Biblioteconomia e CI, mais presente a partir da década de 1930, devido à criação do Doutorado na área.

\section{JESSE SHERA, O HOMEM POR TRÁS DA PROFISSÃO}

Em Oxford (Ohio - EUA), no dia 8 de dezembro do ano de 1903, nascia Jesse Hauk Shera, filho de Charles Hauk Shera e Jessie Hauk Shera. Wright (2013) menciona que Jesse Shera teve um breve flerte com a Sociologia e as Ciências Sociais e foi esse apreço inicial que despertou sua visão mais apurada de pesquisador no decorrer de sua trajetória profissional.

0 contato com a Biblioteconomia foi realmente algo ao acaso. Shera começa a trabalhar em 1927 como assistente de catalogação na Biblioteca da University of Miami. Suas habilidades fizeram com que ele se destacasse em seu trabalho e se tornasse uma espécie de substituto do bibliotecário, conhecido por 'Ned' King, conforme cita Wright (2013). A partir de então, 'Ned' King influencia Shera a entrar para o curso de Biblioteconomia, uma vez que se inquietava com questões do cotidiano da biblioteca e por sua visão sobre as Ciências Sociais, que possibilitaria que grandes estudos fossem desenvolvidos com uma abordagem mais sociológica, e não apenas para resolver problemas técnicos do dia a dia.

Alguns dos questionamentos de Shera comentados por Grossman (2010), tratam da própria atitude dos bibliotecários americanos, que para Shera (apud GROSSMAN, 2010, p. 155, tradução nossa), "sofriam de falta de curiosidade e excesso de timidez, o que os condicionava a realizar uma Biblioteconomia de caráter ortodoxo".

Em 1928, Shera casou-se com May Bickham, também bibliotecária, com quem teve dois filhos: Mary Helen e Edgar Brooks.

Outro ponto importante - e que também influenciou as pesquisas que Shera viria a fazer - diz respeito ao seu envolvimento com a área da Comunicação. Wright (2013) comenta que Shera interessava-se em saber como as pessoas se comunicam umas com as outras e que seu interesse era no próprio processo de troca, o que 
acabou despertando a atenção do teórico para questões relacionadas à recuperação e à própria transferência da informação e do conhecimento.

No decorrer de sua trajetória, Shera acaba voltando-se para as bibliotecas públicas, o que evidencia seu interesse na Sociologia e nas Ciências Sociais, dando pistas de que esse seria o caminho para seus futuros trabalhos. Segundo Hartel (2012), a tese de Shera para obtenção do título de PhD em Library Science na University of Chicago teve como temática um estudo histórico dos movimentos originais das Bibliotecas Públicas em New England (EUA).

Com o avanço da tecnologia e automatização de algumas práticas nas bibliotecas, Shera volta-se para essa temática de estudo e começa a trocar ideias com outros pesquisadores, momento em que começa a ter um contato mais direto com Margaret E. Egan.

Egan tinha interesse em realizar algumas pesquisas a respeito da 'Nova Biblioteconomia' que se formava, mas encontrou dificuldades para participar dos círculos acadêmicos de algumas universidades, entre eles os movimentos ligados à University of Chicago, instituição com a qual a pesquisadora não possuía vínculo. A partir disso, quando surgiu a oportunidade de Shera participar efetivamente do corpo de profissionais da University of Chicago e da Western Reserve, Egan foi uma das suas principais motivadoras, pois, assim, ela teria um aliado na ponte para seus estudos, já que Shera também tinha interesse na temática.

As inquietações do pesquisador eram um ponto forte de sua personalidade e influenciavam diretamente sua carreira. Shera queria pensar uma nova Biblioteconomia que explorasse tanto a educação quanto a automação e o uso de computadores. Wright (2013) comenta que Jesse Shera foi a primeira pessoa que, além de pensar que a Biblioteconomia devia ser vista não apenas como técnica, mas também como profissão, pensava igualmente no modo de sistematizar esse pensamento na Western Reserve, com a instauração de um programa com padrões mais exigentes e um corpo docente apto para trabalhar com pesquisas aprofundadas, bolsas de estudo e trabalhos de extensão.

Foi por volta de 1956 que Shera conseguiu trazer Margaret Egan para a Western Reserve, e é a partir desse momento que ambos conseguem chegar o mais próximo possível de algo concreto em seus estudos porque, naquele ano, já havia vários 'seguidores' das ideias de Shera em estabelecer um novo olhar para a Biblioteconomia.

Em paralelo com as pesquisas na Western Reserve, outro fato curioso mencionado por Grossman (2010) foi o de que Shera e Ranganathan eram amigos e admiradores um do outro, tendo, muitas vezes, trocado correspondências e ideias sobre seus estudos e Shera, inclusive, revisou na época a nova edição da Colon Classification, de Ranganathan. Algumas das ideias da disciplina de Epistemologia Social foram baseadas nas leituras indicadas por Ranganathan e na visita que Shera fez à Índia para participação em um evento no ano de 1967. As leituras recomendadas, de acordo com Zandonade (2004), foram: Library and the individual, Library and society, Library and knowledge, Transition and change e Education of the librarian.

A participação associativa de Shera na American Library Association (ALA), da qual foi membro ativo desde os 27 anos, influenciou grande parte de seu desenvolvimento profissional (GROSSMAN, 2010).

Zandonade (2004) comenta que o periódico brasileiro Ciência da Informação publicou um dos três mais completos textos de Shera que abordam as ideias da disciplina de Epistemologia Social. O nome do documento é 'Epistemologia social, semântica geral e biblioteconomia' e foi publicado no ano de 19777.

\footnotetext{
${ }^{7}$ A referência desse documento está contida nas referências do presente artigo.
} 
Sempre preocupado com os caminhos que tomaria o campo da Biblioteconomia e Ciência da Informação, antes de falecer, vivenciando o tumulto da consolidação da Ciência da Informação como área, Shera indica, por meio de uma declaração (WRIGHT, 2013), algumas inconveniências da suposta área, que se resumem por:

a) Necessidade da Ciência da Informação se provar como uma disciplina;

b) Os computadores devem se adaptar aos bibliotecários, e não o contrário;

c) A Ciência da Informação possui uma profunda crise de identidade;

d) A Ciência da Informação deve ser um complemento da Biblioteconomia.

e) A Ciência da Informação tem mais holofotes do que a Biblioteconomia devido ao seu envolvimento com a matemática e a engenharia tecnológica.

Depois de sua morte, em 8 de março de 1982, Shera tem sido muito analisado criticamente por outros profissionais, conforme cita Hartel (2012). É importante esclarecer que as informações compiladas para a construção desta seção foram baseadas nos dados da obra Jesse Shera, Librarianship, and Information Science, de Herbert Curtis Wright (1928-2012), que foi professor do Department of Library Science na Brigham Young University e, mesmo tendo seguido por pesquisas mais clássicas, teve algumas produções com Shera. Por esse motivo, as curiosidades acerca da vida pessoal de Shera abordadas na obra de Wright tornam-se tão ricas, já que trazem excertos de conversas informais, inclusive entre os pesquisadores citados.

\section{SHERA COMO REFERÊNCIA À BIBLIOTECONOMIA E CIÊNCIA DA INFORMAÇÃO}

Jesse Shera formou-se em Literatura Inglesa no ano de 1925, tornando-se mestre em 1927 pela Yale University, e a partir de então passa a atuar como bibliotecário. Em 1944, doutorou-se em Biblioteconomia pela Graduate Library School da University of Chicago.

Entre 1928 e 1940, trabalhou na Scripps Foundation for Reserach in Population Problems, depois na Library of Congress, de 1940 a 1941, e no Office of Strategic Services, no período de 1941 a 1944. Shera também foi associado da biblioteca universitária e professor de Biblioteconomia na University of Chicago e, em 1950, foi delegado na Conferência Internacional da UNESCO, em Paris, representando os EUA. Em 1951, assume a direção da Escola de Biblioteconomia da Western Reserve University.

Ele sempre defendeu o caráter humanístico da Biblioteconomia, mesmo durante a sua contribuição mais técnica como, por exemplo, a criação do catálogo sistemático que visava a melhor recuperação da informação do ponto de vista do usuário.

Foi pesquisador da University of Chicago nos estudos sobre as relações entre biblioteca e sociedade. De acordo com Araújo et al. (2010), a obra mais citada do autor e também uma das mais relevantes é o capítulo de livro 'Sobre biblioteconomia, documentação e ciência da informação'. Outro artigo interessante de Shera, publicado em 1968, intitula-se 'Sobre Biblioteconomia e Ciência da Informação" e "descreve o processo paulatino de desmembramento da Ciência da Informação do campo da Biblioteconomia." (SILVA, 2012, p. 5).

Shera (1972, apud SARACEVIC, 1996, p. 49) acredita que as bibliotecas devem sempre estar

[...] contribuindo para o sistema total de comunicação na sociedade [...] Embora as bibliotecas tenham sido criadas como instrumentos para maximizar a utilização dos registros gráficos em benefício da sociedade, elas atingem sua meta trabalhando com os indivíduos e através deles, atingem a sociedade. 
Portanto, para o autor, a razão de ser da Biblioteconomia e de seus fundamentos está justamente no seu fazer social e na significância do papel da biblioteca perante a sociedade. Bufrem (1985) ainda complementa que, na visão de Shera, é preciso entender os papeis que a biblioteca desempenhou no decorrer de sua história, para que seja possível entender a Biblioteconomia de hoje.

Especializando-se nas relações entre a Ciência da Informação e a Biblioteconomia, Shera e sua colaboradora Margaret Egan propõem uma disciplina chamada "Epistemologia Social", que, a princípio, desenvolveria uma teoria da bibliografia.

Por meio de seus estudos, Shera conclui que "a marca da epistemologia social consiste em que ela coloca a ênfase no ser humano e na sociedade como um todo, e todas as suas formas de pensar, conhecer, agir e comunicar." (SHERA, 1973, p. 90). Seria, portanto, "o estudo do ciclo que envolve a produção, a circulação e o uso do conhecimento, caracterizado em sua materialidade como uma verdadeira ecologia sociotécnica do trabalho intelectual." (ODDONE, 2007, p. 110).

Shera (1973, p. 89) ainda complementa dizendo que a filosofia socioepistemológica proposta não exclui a importante contribuição das ciências exatas absorvidas pelas práticas bibliotecárias, mas enfatiza que o que hoje chamamos de campo da Biblioteconomia e Ciência da Informação deveria perceberse dentro das ciências sociais.

\section{HUMANISMO EM SHERA}

A Ciência da Informação, segundo a literatura da área, nasce nas revoluções científicas e técnicas do pós-guerra, em meio às problemáticas de acesso e recuperação da informação. Segundo Oliveira (2011, p.13):
A ênfase nessa atividade que veio a se denominar Ciência da Informação deve-se ao seu esforço para enfrentar os problemas de organização, crescimento e disseminação do conhecimento registrado, que vem ocorrendo em proporções geométricas, desde logo após a Segunda Guerra Mundial. Nesse sentido, a Ciência da Informação nasceu para resolver um grande problema, que foi também a grande preocupação tanto da Documentação quanto da Recuperação da Informação, que é o de reunir, organizar e tornar acessível o conhecimento cultural, científico e tecnológico produzido em todo o mundo.

Para outros autores, entretanto, a terminologia dos estudos que hoje conhecemos como a área da Ciência da Informação variou muito no decorrer dos anos. 0 primeiro registro data de 1802, com o termo bibliografia. Em seguida, têmse os termos librarianship (1818) e Library Science (1851). Em 1903, aparece o termo documentação (traduzido em 1908), cunhado por Paul Otlet. Somente em 1950 aparece o termo information retrieval, cunhado por Calvin Mooers, e em 1960 é que, finalmente, tem-se o termo Information Science (Ciência da Informação). Esse termo foi registrado pela primeira vez, de acordo com Alvares e Araújo Júnior (2010), pelo Oxford English Dictionary, em 1958.

No Brasil, conforme os consultores do CNPq, a

ciência da informação designa o campo mais amplo, de propósitos investigativos e analíticos, interdisciplinar por natureza, que tem por objetivo o estudo de fenômenos ligados à produção, organização e difusão e utilização de informações em todos os campos do saber. (OLIVEIRA, 2001, p. 143)

Existem, no entanto, diferentes teorias acerca do surgimento da CI e suas principais áreas de relacionamento. Capurro (2003) menciona três paradigmas da 
CI: o físico (vê a informação como 'coisa' que é transferida de um ponto a outro); o cognitivo (a informação é vista como um elemento alterador da mentalidade do usuário); e o social (procura entender a informação por parte dos seus usuários). A partir disso, vê-se que a CI não é puramente uma ciência social, pois possui forte ligação com a computação e a recuperação da informação, sobretudo em sua fase tecnológica. Contudo, um dos paradigmas da CI abordados por Capurro aponta para o lado social, e é para esse paradigma que esta pesquisa está voltada.

Com o movimento em prol das Bibliotecas Públicas, já mencionado anteriormente, o campo da Biblioteconomia e Ciência da Informação começa a tornar-se reconhecido, tendo em vista a formação de usuários, que antes não possuíam acesso às bibliotecas, e a necessidade de uma organização e disseminação da informação que estava sendo produzida em grande quantidade após a Segunda Guerra Mundial. Porém, a CI teve grandes dificuldades em se firmar como uma área de conhecimento autônoma, pois foi (e ainda é) considerada por alguns pesquisadores como uma área derivada da Biblioteconomia ou da Documentação europeia.

Essa discussão incluía também algumas interpretações sobre a possibilidade da CI tomar, em alguma medida, o espaço da Biblioteconomia, mas "nos países anglo-saxões e nórdicos, prevaleceu a ideia de uma grande área chamada 'Biblioteconomia e Ciência da Informação'” (ARAÚJO, 2011, p. 116), entendida e utilizada neste trabalho como o campo da Biblioteconomia e Ciência da Informação.

Pode-se dizer que tanto os estudos da área da Biblioteconomia quanto da chamada área da Ciência da Informação colaboraram uma com a outra, a partir do momento em que a CI passou a ser reconhecida por sua cientificidade à produção de conhecimentos biblioteconômicos e a partir do momento em que a Biblioteconomia passou a oferecer infraestrutura institucional e diversidade de temáticas que poderiam vir a ser trabalhadas pela Ciência da Informação.

Para alguns autores, como Carvalho (2016), Capurro e Hjørland (2007), a Biblioteconomia contribui para a construção epistemológica da CI e auxilia de forma determinante seus estudos acerca da organização e tratamento da informação e sobre a própria recuperação da informação.

Por outro lado, alguns pesquisadores compartilham da ideia de que a Ciência da Informação nasce na Biblioteconomia. Quanto a isso, Le Coadic (2004, p.2) deixa seu ponto de vista bem explícito quando afirma que "de origem anglo-saxônica, a Ciência da Informação nasceu da Biblioteconomia, tomando, assim, como objeto de estudo a informação fornecida pelas bibliotecas, fossem públicas, universitárias, especializadas ou centros de documentação".

Para Shera (1980), a CI é uma disciplina aliada à Biblioteconomia e ainda complementar. Embora a linguagem entre bibliotecários e cientistas da informação não seja a mesma, as noções da época do surgimento da Ciência da Informação exigiam uma nova terminologia que poderia ser acordada para que fosse possível uma compreensão mútua. $\mathrm{O}$ autor também ressalta o papel social da Biblioteconomia em seus trabalhos e o estende para a $\mathrm{CI}$, sempre fazendo um paralelo, quanto ao compromisso social, entre a sociedade e a profissão.

Quando Shera menciona a recuperação da informação, enfatiza que por mais precisos que sejam os mecanismos utilizados, não há valor se essa informação não estiver acessível para o usuário. Mesmo com a tecnologia, a máquina não é nada se não for bem utilizada pelo humano, e é esse o ponto determinante que precisamos utilizar para interligar nossas ações dentro do campo da Biblioteconomia e Ciência da Informação, compreendendo que nossas técnicas só serão bem-sucedidas se alcançarem o usuário, se cumprirmos o compromisso social da profissão.

0 teórico afirma que a sociedade, inquieta com o avanço tecnológico, deveria domar essas máquinas e aprender a viver com elas, devendo olhar a epistemológica social como sendo uma "aculturação da máquina" (SHERA, 1977, p.11). Wright 
(2013) menciona, ainda, que Shera acreditava que a tecnologia deveria contribuir para expandir as dimensões dos serviços da biblioteca.

No artigo 'Epistemologia Social, semântica geral e Biblioteconomia', publicado em 1977, Shera ressalta a importância de se pensar no impacto social que as práticas biblioteconômicas possuem, bem como na forte relação entre informação e sociedade, evidenciada no trecho: "Assim como a necessidade de informação orienta o indivíduo, assim também orienta sociedades. É a base do comportamento coletivo, tanto quanto do comportamento individual" (SHERA, 1977, p. 10).

Enfim, Shera (1973) estabelece que a Ciência da Informação deve ser vista como uma ciência social, ressaltando a importância da epistemologia social nos estudos da CI, pois é preciso ter a ênfase voltada para o ser humano, mesmo quando tratamos de questões técnicas ou tecnológicas.

\section{CONSIDERAÇÕES FINAIS}

Os próprios estudos e a atuação profissional de Jesse Shera são reflexos dos movimentos que influenciaram a criação da vertente humanística da Biblioteconomia e Ciência da Informação, entre os quais se destacam a École Nationale des Chartes e o movimento da Escola de Chicago, onde foi membro e desenvolveu pesquisas voltadas para o lado humanístico de sua área de atuação.

Shera foi - e ainda é - um nome que deve ser lembrado por seu empenho em procurar mostrar que a Biblioteconomia não é feita só de livros catalogados, que o usuário não é só aquele que passa pelo empréstimo e devolução, que os computadores são nossos instrumentos de trabalho, que a Ciência da Informação é uma continuação da Biblioteconomia e que ambas possuem seus princípios pautados no fazer social e na vertente humanística, por mais técnico ou tecnológico que seja sua atividade cotidiana.

É importante ressaltar que por mais imparcial que um pesquisador seja, sua vida e seus caminhos influenciam em sua visão e atuação. Prova disso é a participação de Shera no movimento da Escola de Chicago e seu apreço pela Sociologia, que guiou o seu fazer profissional e a própria base teórica de seus estudos.

É muito difícil mensurar a importância de um teórico para o campo, quando suas contribuições nem sempre são abordadas com a devida profundidade. Porém, nesta pesquisa, tentou-se pelo menos elencar quais seriam essas contribuições, de modo a permitir que outros pesquisadores possam adentrar nesses estudos focando a aplicabilidade destes para sua área de atuação.

Acredita-se que seria de grande valia para o campo a realização de outras pesquisas que se aprofundassem no tema Escola de Chicago e sua influência para a Ciência da Informação, devido à sua grande significância para a vertente humanística da área, bem como a produção de outros estudos visando teóricos que, assim como Jesse Shera, são pouco abordados na literatura brasileira.

\section{REFERÊNCIAS}

ALMEIDA, Neilia Barros Ferreira de; BAPTISTA, Sofia Galvão. Breve histórico da Biblioteconomia brasileira: formação do profissional. In: CONGRESSO BRASILEIRO DE BIBLIOTECONOMIA, DOCUMENTO E CIÊNCIA DA INFORMAÇÃO, 15., 2013, Florianópolis. Anais eletrônico... . Florianópolis: 2013. Disponível em: https://goo.gl/7b7M6E. Acesso em: 12 jan. 2017.

ALVARES, Lillian; ARAÚJO JUNIOR, Rogério Henrique de. Marcos históricos da Ciência da Informação: breve cronologia dos pioneiros, das obras clássicas e dos eventos fundamentais. 
Transinformação, Campinas, v. 22, n. 3, p. 195-205, Dec. 2010. Disponível em: https://goo.gl/CQil4J . Acesso em: 12 jan. 2017.

ARAUJO, Andre Vieira de Freitas. Pioneirismo bibliográfico em um polímeta do séc. XVI: Conrad Gesner. Informação \& Informação, Londrina, v. 20, n. 2, p. 118-142, maio 2015. Disponível em: https://goo.gl/jiuZwk. Acesso em: 12 jan. 2017.

ARAÚJO, Carlos Alberto Ávila. Condições teóricas para a integração epistemológica da Arquivologia, Biblioteconomia e Museologia na Ciência da Informação. InCID, Ribeirão Preto, v. 2, n. 2, p. 19-41, jul./dez. 2011. Disponível em: https://goo.gl/jS1JUB. Acesso em: 12 jan. 2017.

. Ciência da informação, biblioteconomia, arquivologia e museologia: relações institucionais e teóricas. Encontros Bibli, Florianópolis, v. 16, n. 31, p. 110-130, 2011. Disponível em: https://goo.gl/PDrFBE Acesso em: 12 jan. 2017.

et al. A contribuição de J. H. Shera para a ciência da informação no Brasil. Revista ACB, Florianópolis, v. 15, n. 2, p. 71-89, jul. 2010. Disponível em: https://goo.gl/aTPdu2 . Acesso em: 12 jan. 2017.

BOURDIEU, Pierre. Os usos sociais das ciências: por uma sociologia clínica do campo científico. São Paulo: UNESP, 2004.

BECKER, Howard. A escola de Chicago. Mana, Rio de Janeiro, v. 2, n. 2, p. 177-188, Oct. 1996. Disponível em: https://goo.gl/iwxoB2 . Acesso em: 12 jan. 2017.

BUFREM, Leilah Santiago. Fundamentos sociais e políticos da biblioteconomia. Educar, Curitiba, n. 4, p. 108-122, dez. 1985. Disponível em: https://goo.gl/r1tyd8 . Acesso em: 12 jan. 2017.

CAPURRO, Rafael. Epistemologia e ciência da informação. In: ENCONTRO NACIONAL DE PESQUISA EM CIÊNCIA DA INFORMAÇÃO, 5., 2003, Belo Horizonte. Anais... Belo Horizonte: Associação Nacional de Pesquisa e Pós-Graduação em Ciência da Informação e Biblioteconomia, 2003. Disponível em: https://goo.gl/OsycU6 Acesso em: 12 jan. 2017.

; HJØRLAND, B. O conceito de informação. Perspectivas em Ciência da Informação, Belo Horizonte, v. 12, n. 1, p. 148-207, abr. 2007. Disponível em: https:/goo.gl/G7V4iu . Acesso em: 12 jan. 2017.

CARVALHO, Jonathas. Tópicos em biblioteconomia e ciência da informação: epistemologia, política e educação. Rio de Janeiro: Agência Biblioo, 2016.124 p.

DIAS, Eduardo Wense. Biblioteconomia e ciência da informação: natureza e relações.

Perspectiva em Ciência da Informação, Belo Horizonte, v. 5, n. especial, p. 67-80, jan./jun. 2000. Disponível em: < https://goo.gl/mrJZcu> . Acesso em: 12 jan. 2017.

DICIONÁRIO informal. 2016. Disponível em: https://goo.gl/mOznlQ Acesso em: 12 jan. 2017.

FONSECA, Edson Nery da. Introdução a Biblioteconomia. 2. ed. Brasília, DF: Lemos Informação e Comunicação 2007.

GIGANTE, Maristela Cid. Os sistemas de classificação bibliográfica como interface biblioteca/usuário. Ciência da Informação, [S.l.], v. 25, n. 2, aug. 1995. ISSN 1518-8353. Disponível em: https://goo.gl/4d6Uad . Acesso em: 12 jan. 2017.

GROSSMAN, Hal B. 'Without Reserve': Jesse Shera in the Wilson Library Bulletin and Elsewhere 1961-1970. Library and Information History, v. 26, n. 2, p. 152-69, jun. 2010. Disponível: https://goo.gl/dWxuG5 Acesso em: 12 jan. 2017.

GUIMARÃES, José Augusto Chaves. Moderno profissional da informação: elementos para sua formação no Brasil. Ciência da Informação, Brasília, v.9, n.1, jan./abr., 1997. Disponível em: https://goo.gl/uJc97h . Acesso em: 12 jan. 2017.

HARTEL, Jenna. Welcome to library and information Science. Journal of Education for Library and Information Science, v. 53, n. 3, jul. 2012. Disponível em: https://goo.gl/CiScxj Acesso em: 12 jan. 2017. 
LANKES, David. Expect more: demanding better libraries for today's complex world. 2013. Disponível em: https://goo.gl/a8pQfM . Acesso em: 12 jan. 2017.

LE CODIAC, Yves-François. A ciência da informação. 2 ed. Brasília, DF: Lemos Informação e Comunicação. 2004. 124 p.

MACEDO, Tony Bernardino. Ciência da informação: uma abordagem para a transformação. In: CONGRESSO BRASILEIRO DE BIBLIOTECONOMIA, DOCUMENTO E CIÊNCIA DA INFORMAÇÃO, 15., 2013, Florianópolis. Anais eletrônico...Florianópolis: 2013. Disponível em: https://goo.gl/BQIz9c . Acesso em: 12 jan. 2017.

ODDONE, Nanci. Revisitando "epistemologia social": esboço de uma ecologia sociotécnica do trabalho intelectual. Ciência da Informação, Brasília, v. 36, n. 1, p.108-123, jan./abr. 2007. Disponível em: https://goo.gl/685Gaw. Acesso em: 12 jan. 2017.

OLIVEIRA, Marlene de. A pesquisa científica na Ciência da Informação: análise da pesquisa financiada pelo CNPq. Perspectivas em Ciência da Informação. Belo Horizonte, v. 6, n. 2, p. 143-156, jul./dez. 2001. Disponível em: https://goo.gl/Ako68K Acesso em: 12 jan. 2017.

Ciência da informação e biblioteconomia: novos conteúdos e espaços de atuação. 2 ed. Belo Horizonte: Ed. UFMG, 2011, 139 P. (Didática)

ORTEGA, Cristina Dotta. Relações históricas entre Biblioteconomia, Documentação e Ciência da Informação. DataGramaZero, v. 5, n. 5, out., 2004. Disponível em:

https://goo.gl/J6QHfD> Acesso em: 12 jan. 2017.

ORTEGA Y GASSET, José. Misión del bibliotecario. 2. ed. Madrid: Revista de Occidente, 1967. 83p

RIBEIRO, Paulo Silvino. "A Escola de Frankfurt". Brasil Escola. 2016. Disponível em https://goo.gl/1Seoyb Acesso em 12 jan, 2017.

SANTOS, Ana Paula Lima dos; RODRIGUES, Mara Eliane Fonseca. Biblioteconomia: gênese, história e fundamentos. Revista Brasileira de Biblioteconomia e Documentação, São Paulo, v. 9, n. 2, p. 116-131, jul./dez. 2013. Disponível em: https://goo.gl/CDDhGi. Acesso em: 12 jan. 2017.

SARACEVIC, Tefko. Ciência da informação: origem, evolução e relações. Perspectivas em Ciência da Informação. Belo Horizonte, v. 1, n.1, p. 41-62, jan./jul. 1996. Disponível em: https://goo.gl/4IEtNz . Acesso em: 12 jan. 2017.

SHERA, Jesse. Epistemologia social, semântica geral e biblioteconomia. Ciência da Informação, [S.l.], v. 6, n. 1, jun. 1977. ISSN 1518-8353. Disponível em: https://goo.gl/ahvxEF . Acesso em: 12 jan. 2017. doi:http://dx.doi.org/10.18225/ci.inf.v6i1.92.

. Sobre biblioteconomia, documentação e ciência da informação. In: GOMES, Hagar Espanha (org.) Ciência da Informação ou informática? Rio de Janeiro: Calunga, 1980. 112 p. (Série Ciência da Informação).

. Toward a theory of Librarianship and information science. Ciência da Informação, Rio de Janeiro, v. 2, n. 2, dez. 1973. Disponível em: https://goo.gl/145VPs. Acesso em: 12 jan. 2017.

SILVA, Marco Donizete Paulino da. A evolução da ciência da informação a partir de conceitossinônimos empregados na obra ciência da informação ou informática? Encontros Bibli, Florianópolis, v. 17, n. 34, p.1-16, maio/ago. 2012. Disponível em: https://goo.gl/cX0b6N. Acesso em: 12 jan. 2017.

SILVA, Jonathas Luiz Carvalho; FREIRE, Gustavo Henrique de Araújo. Um olhar sobre a origem da ciência da informação: indícios embrionários para sua caracterização identitária. Encontros Bibli, v. 17, n. 33, p.1-29, jan./abr. 2012. Disponível em: https://goo.gl/MLEbmL. Acesso em: 12 jan. 2017.

SIQUEIRA, Jéssica Câmara. Biblioteconomia, documentação e ciência da informação: história, sociedade, tecnologia e pós-modernidade. Perspectiva em Ciência da Informação, Belo 
Horizonte, v. 15, n. 3, p. 52-66, set./dez. 2010. Disponível em: https://goo.gl/mrJZcu . Acesso em: 12 jan. 2017.

WRIGHT, Herbert Curtis. Jesse Shera, Librarianship and Information Science.

Sacramento (CA): Library Juice Press, 2013.

ZANDONADE, Tarcisio. Social epistemology from Jesse Shera to Steve Fuller. Library

Trends, v. 52, n. 4, p. 810-832. 2004. Disponível em: https://goo.gl/6pmFAK. Acesso em: 12 jan. 2017. 